\title{
Long-Term Impact in Hepatitis C Virus Infection in Post Renal Transplantation
}

\author{
Euler Pace Lasmar*, Marcus Faria Lasmar, Leonardo Faria Lasmar, Adalberto Fernandes Nogueira, \\ Marina Ribeiro de Oliveira Santos, Luiz Flavio Couto Giordano, Heloisa Reniers Vianna \\ Kidney Transplant Unit of Sao Jose University Hospital and Mater Dei Hospital, Belo Horizonte, Brazil \\ Email: *lasmar@superig.com.br
}

Received April 20, 2012; revised May 6, 2012; accepted June 1, 2012

\begin{abstract}
Purpose: The authors have evaluated the impact of the kidney transplantation associated with chronic hepatitis $\mathrm{C}$ virus (HCV) infection, analyzing the complications, patients and graft survival. Methods: Retrospective study with 40 kidney transplant recipients with HCV infection and 40 kidney transplant recipients without HCV infection in the same post transplantation period. Results: The average follow-up after transplantation was $12.3 \pm 4.5$ years in patients with HCV infection and $12.5 \pm 2.9$ years in patients without HCV infection $(\mathrm{p}=0.49)$. There was no statistical difference related to age and gender of the recipient nor donor age and type. The current renal function in patients with HCV infection was $47.3 \pm 24.9 \mathrm{~mL} / \mathrm{min}$ and $54.9 \pm 27.2 \mathrm{~mL} / \mathrm{min}$ in the HCV negative group $(\mathrm{p}=0.54)$. The incidence of graft and patient survival was similar in both groups. The main cause of death in both groups was bacterial infection $(10 \%$ in patients with HCV infection and $12.5 \%$ in HCV negative patients $(\mathrm{p}=0.63)$. The most common complication in the two groups were acute allograft rejection and bacterial infection. The incidence of diabetes mellitus did not differ statistically in both groups. Abnormal liver enzymes levels and cirrhosis were observed only in patients with HCV infection. Conclusion: HCV infection did not impact patient or graft survival and post-transplant complications were similar in both groups during a mean follow-up period of 12 years.
\end{abstract}

Keywords: HCV; Kidney Transplantation; Chronic Kidney Failure

\section{Introduction}

The hepatitis C virus infection (HCV) is the main cause of chronic liver disease in patients with chronic kidney disease in dialysis treatment and post-transplantation. The prevalence of HCV varies according to regions and countries, ranging from $3 \%$ to $80 \%$ in patients on dialysis treatment and $10 \%$ to $41 \%$ in kidney transplant recipients [1-3].

Patients with end-stage renal disease and HCV infection in transplant waiting list show a higher mortality risk compared to those submitted to renal transplant (Tx) and this risk increases with time [3-5].

Although there were improvements in the result of the kidney transplant, some publications have shown that chronic liver disease secondary to HCV infection represents one of the main causes of morbidity and mortality in immunocompromised patients [6].

It is controversial in medical literature if HCV has detrimental effects on patients and graft survival [7-11]. The purpose of this study was to observe the impact of chronic HCV infection in renal transplant recipients, com-

${ }^{*}$ Corresponding author. pared to matched HCV negative patients. The pre-liminary data of this study were published previously [12].

\section{Methods}

Forty patients with HCV infection and forty patients without HCV infection submitted to renal transplant in our institution were selected retrospectively and analyzed. The HCV positive $(\mathrm{HCV}+)$ patients had been submitted to liver biopsy prior to renal transplantation, and none presented active chronic hepatitis or cirrhosis. The control patients (HCV-) had also been transplanted in our institution and were selected using demographic characteristics in order to closely resemble the HCV+ patients. The following variables were analyzed: age, gender and race of the receivers, donor types, HLA profile, time of the transplantation, current kidney function, graft and patient survival, time and cause of graft loss or death, immunosuppressive drugs and complications. The presence of anti-HCV antibodies was tested before and many times after transplantation, using Elisa method of first generation, in the period from 1990 to 1992, second generation from 1992 to 1997 and third generation after that. The renal function was evaluated by the creatinine clear- 
ance through the formula of Cochroft-Gault. HCV phenotype determination was not done because this constitutes a retrospective study. The cause of the renal insufficiency could not be established in 37 patients (46.2\%); 26 patients (32.5\%) had chronic glomerulonephritis; five patients (12.5\%) had adult polycystic kidney disease; five patients (12.5\%) had hypertensive nephrosclerosis; four patients $(1.0 \%)$ had chronic interstitial nephritis; two patients $(0.5 \%)$ had diabetic nephropathy and one patient (0.25\%) had Alport's disease.

\section{Statistical Analysis}

For comparison of quantitative variables the Mann-Whitney test was used. When the analysis involved qualitative variables the Qui-Square test or the accurate test of Fisher were used, with the level of significance of 5\%, (p $=0.05$ ). Actuarial curves of graft and patients survival were performed using the Kaplan-Meier method.

\section{Results}

The follow-up after transplantation was $12.3 \pm 4.5$ years in patients with HCV infection and $12.5 \pm 2.9$ years in HCV negative patients $(p=0.49)$. Table 1 shows the demographic characteristics of both groups. There was no statistical difference related to age and gender of the recipient nor donors' age, gender and if the donor was living or deceased. The incidence of haploidentical HLA was higher in patients without HCV infection ( $p=0.05)$. The current renal function in patients with HCV infection was $47.3 \pm 24.9 \mathrm{~mL} / \mathrm{min} / 1.73 \mathrm{~m}^{2}$ and $54.9 \pm 27.2$ $\mathrm{mL} / \mathrm{min} / 1.73 \mathrm{~m}^{2}$ in the HCV negative group $(\mathrm{p}=0.48)$. Time, measured in months, until the graft loss was $36.1 \pm$ 3.1 in patients with HCV infection and $47.7 \pm 40.6$ in the $\mathrm{HCV}$ negative group ( $\mathrm{p}=0.67)$. Death was the main cause of graft loss in both groups (HCV+: 14 patients,

Table 1. Dem ographic profile and major outcomes.

\begin{tabular}{lccc}
\hline & HCV + & HCV - & p-value \\
\hline Age (recipient) & $37.3 \pm 17.3$ & $32.8 \pm 12.4$ & 0.09 \\
Age (donor) & $32.0 \pm 10.3$ & $33.8 \pm 12.5$ & 0.4 \\
Gender (M, F) & $31 / 10$ & $27 / 13$ & 0.31 \\
Race (W, MU, BL) & $28 / 6 / 6$ & $38 / 1 / 1$ & 0.08 \\
Type of donor (RLD, NRLD, DD) & $17 / 1 / 22$ & $2 / 23 / 2015$ & 0.11 \\
HLA (HD, HI, I, NA) & $3 / 8 / 0 / 29$ & $4 / 16 / 2 / 18$ & 0.05 \\
Follow-up (years) & $12.3 \pm 4.5$ & $12.5 \pm 2.9$ & 0.49 \\
Current creatinine clearence & $47.3 \pm 24.9$ & $54.9 \pm 27.2$ & 0.48 \\
(mL/min/1.73cm $\left.{ }^{2}\right)$ & $28(70 \%)$ & $34(85 \%)$ & 0.48 \\
Graft loss & $14(35 \%)$ & $13(32.5 \%)$ & 0.22 \\
Death & &
\end{tabular}

$\mathrm{M}=$ Male; $\mathrm{F}=$ Female; $\mathrm{W}=$ White; $\mathrm{MU}=$ Mulatto; $\mathrm{BL}=$ Black; RLD = Related living donor; DD = Deceased donor; HD = Haplo different; $\mathrm{HI}=$ Haplo identical; I = Identical; NA = Not analyzed.
HCV-: 13 patients), followed by intersticial fibrosis/tubular atrophy (IFTA) which was more commun in HCV negative patients $(30.0 \%$ versus $15.5 \%)(p=0.03)$ (Table 2). Patient survival was $65 \%$ in patients with $\mathrm{HCV}$ infection and $67.5 \%$ in HCV negative patients ( $\mathrm{p}=0.545$ ) (Figure 1) and patients with HCV infection died earlier (18.0 \pm 30.2 months $\times 49.8 \pm 58.7$ months, $p=0.03)$. Graft survival was similar in both groups, $30 \%$ in HCV positive patients and $40 \%$ in patients without HCV infection ( $p=0.24)$ (Figure 2).

The main cause of death in both groups was bacterial infection: $10.0 \%$ in patients with $\mathrm{HCV}$ infection and $12.5 \%$ in the HCV negative group ( $p=0.63$ ) (Table 3). There was no statistical difference related to immunosuppressive therapy in both groups ( $p=0.87$ ), predominating the following protocol: cyclosporine (CSA), azathioprine (AZA) and prednisone (PRED) (Table 4).

The initial immunosuppressive therapy dose in both groups was similar and consisted of CSA (8 mg/kg/day), TAC (0.2 mg/kg/day), AZA (2 mg/kg/day), mycophenolate mofetil (MMF) (2.0 g/day), PRED (0.5 mg/kg/day). Table 5 shows the immunosuppressive treatment dose in both groups at the time of final analysis. Steroid withdrawal was not performed.

Table 2. Causes and time until graft loss.

\begin{tabular}{lccc}
\hline & HCV + & HCV- & p-value \\
\hline Time until graft loss (months) & $36.1 \pm 3.1$ & $47.7 \pm 40.6$ & 0.67 \\
Cause of graft loss_-death & $14(35 \%)$ & $13(32.5 \%)$ & 1.00 \\
Cause of graft loss_-IFTA & $6(15.02)$ & $12(30.0 \%)$ & 0.03 \\
Cause of graft loss-others & $21(52.5 \%)$ & $15(37.5 \%)$ & 0.04 \\
\hline
\end{tabular}

IFTA = Intersticial fibrosis tubular atrophy.

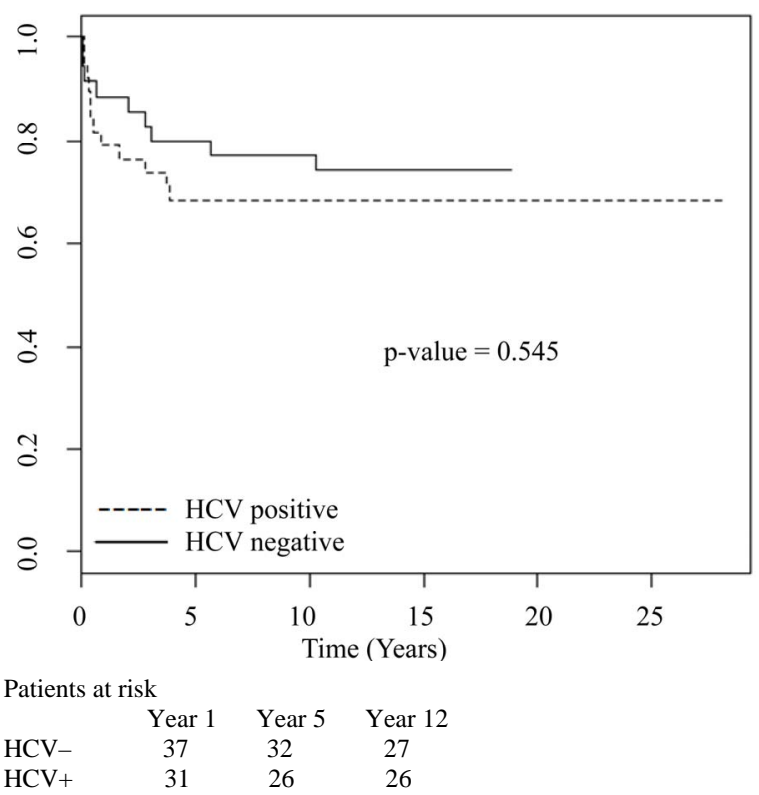

Figure 1. Patient survival. 


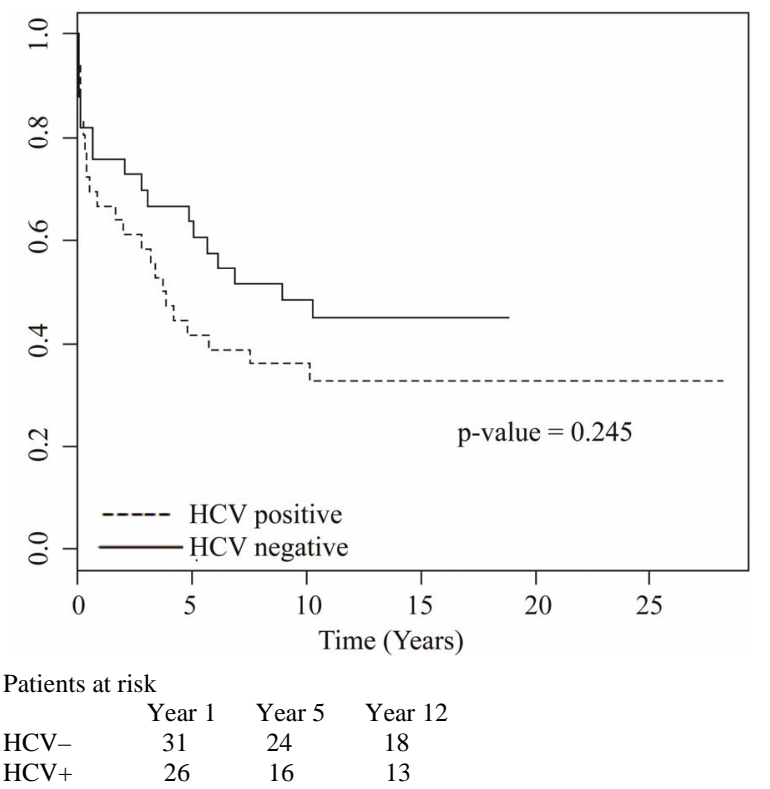

Figure 2. Graft survival.

Table 3. Time until death and its causes.

\begin{tabular}{lccc}
\hline & $\mathrm{HCV}+$ & $\mathrm{HCV}-$ & $\mathrm{p}$ \\
\hline Time until death (months) & $18.0 \pm 30.2$ & $49.8 \pm 58.7$ & 0.03 \\
Death cause-bacterial infections & 5 & 4 & 0.63 \\
Death cause-lung cancer & 1 & 0 & - \\
Death cause-pulmonary hemorrhage & 0 & 1 & - \\
Death cause-retroperitoneal hemorhage & 1 & 0 & - \\
Death cause-lymphoma & 1 & 0 & - \\
Death cause-others & 2 & 2 & - \\
Death cause-undetermined & 4 & 6 & - \\
\hline
\end{tabular}

Table 4. Immunosuppressive therapy.

\begin{tabular}{lccc}
\hline Type & HCV+ & HCV- & p-value \\
\hline CSA + AZA + PRED & $29(72.5 \%)$ & $28(70.0 \%)$ & 0.87 \\
CSA + AZA + PRED + OKT3 & $5(12.5 \%)$ & $7(17.5)$ & 0.4 \\
CSA + AZA + PRED + BAS & $1(2.5 \%)$ & $1(2.5 \%)$ & 1.0 \\
CSA + MMF + PRED & $3(7.5 \%)$ & $2(5.0 \%)$ & 0.85 \\
CSA + SRL + PRED & $1(2.5 \%)$ & $1(2.5 \%)$ & 1.0 \\
TAC + MMF + PRED & $1(2.5 \%)$ & $1(2.5 \%)$ & 1.0 \\
\hline
\end{tabular}

$\mathrm{CSA}=$ Cyclosporine; $\mathrm{AZA}=$ Azathioprine; $\mathrm{OKT} 3=$ Orthoclone; $\mathrm{BAS}=$ Basiliximab; SRL = Sirolimus; TAC = Tacrolimus; PRED = Prednisone.

Table 5. Maintenance dose of immunosuppressive agents in $\mathrm{HCV}+$ and HCV- patients.

\begin{tabular}{ccccc}
\hline Immunosuppressor & HCV & Mean & Standard deviation & p-value \\
\hline \multirow{2}{*}{ CSA } & - & 2.65 & 0.32 & 0.00 \\
& + & 2.10 & 0.14 & 0.00 \\
AZA & - & 1.25 & 0.23 & \\
& + & 0.77 & 0.14 & 0.77 \\
TAC & - & 0.035 & 0.02 & 0.48 \\
& + & 0.036 & 0.01 & \\
PRED & - & 0.09 & 0.04 & 0.62 \\
& + & 0.085 & 0.02 & \\
\hline
\end{tabular}

The incidence of acute rejection was 35\% in the HCV positive group and $25 \%$ in patients without HCV in-fection ( $p=0.26)$ and the most common complication in both groups was acute cellular rejection and bacterial infection. The incidence of new onset diabetes mellitus did not differ statistically. Abnormal levels of liver enzymes (AST, ALT and GGT) and cirrhosis were observed only in patients with HCV infection (Table 6).

\section{Discussion}

The natural history of the HCV hepatitis in post-renal transplantation has not been well established. Some authors believe that the immunosuppressive therapy facilitates the viral proliferation and aggravates the liver disease $[13,14]$. However, an increase in viremia may not be associated with a higher risk of liver disease after the renal transplant $[6,15,16]$. According to the literature, the poorer outcomes after kidney transplantation in patients with $\mathrm{HCV}$ infection are mainly due to liver disease and bacterial infection [7,13,14,17]. In the long-term, death has been attributed to complications of chronic liver disease in $8 \%$ to $28 \%$ of the cases $[1,5]$. In the present study, the main cause of death in both groups was bacterial infection. In the HCV positive group, only one patient had liver cirrhosis and in three individuals abnormal liver enzymes levels were detected. Several publications with longer follow-ups have demonstrated that mortality was significantly higher in HCV positive patients [9,18]. In this study, patients survival in both groups was similar, but death occurred earlier in patients with HCV infection. However, one must take into account the small sample size which is a limitation of the present study.

Graft survival was similar in both groups, which is in accordance with some publications in literature [14, 19-22]. If patients with HCV infection have a greater risk of the acute cellular rejection is controversial, with some publications showing a higher incidence of rejection in patients with HCV infection when compared to a HCVnegative control group [13,23,24,27]. In the present study, however there was no statistical difference in the incidence of the acute allograft rejection comparing both

Table 6. Post-transplant complications.

\begin{tabular}{lccc}
\hline Type & HCV + & HCV- & p-value \\
\hline Acute rejection & $14(35.0 \%)$ & $10(25.0 \%)$ & 0.36 \\
Bacterial infections & $9(22.5 \%)$ & $10(25.0 \%)$ & 0.79 \\
Acute tubular necrosis & $9(22.5 \%)$ & $6(15.0 \%)$ & 0.39 \\
Nephrotoxicity od CSA & $6(15.0 \%)$ & $6(15.0 \%)$ & 1.00 \\
Cytomegalovirus & $3(7.5 \%)$ & $1(2.5 \%)$ & 0.61 \\
Abnormal levels of liver enzymes & $2(5.0 \%)$ & 0 & 0.47 \\
NODAT & $5(12.5 \%)$ & $1(2.5 \%)$ & 0.2 \\
Cirrhosis & $1(2.5 \%)$ & 0 & 0.00 \\
\hline
\end{tabular}


groups. The prevalence of new onset diabetes mellitus in the present study was low and without statistical differences between the groups, in contrast with other studies that report a greater risk of this condition in $\mathrm{HCV}$ positive patients $[25,26,28]$. Cyclosporine was the main calcineurin-inhibitor used and in this study, and is reportedly less diabetogenic than tacrolimus, expecially in patients with HCV infection [29]. This could also explain the low incidence of complications in $\mathrm{HCV}$ positive patients. Ony two patients received tacrolimus, a potentially diabetogenic drug specially in patients with HCV infection.

\section{Conclusion}

This study showed that the HCV infection did not impact on patient or graft survival in this non-concurrent cohort. The small sample size limits firm conclusions of the real burden of HCV infection on the renal transplant population. Post-transplant complications (bacterial infection, acute allograft rejection and chronic liver disease) were similar in both groups.

\section{REFERENCES}

[1] F. Fabrizi, F. F. Poodad and P. Martin, "Hepatitis C Infection and the Patient with End-Stage Renal Disease," Hepatology, Vol. 36, No. 1, 2002, pp. 3-10. doi:10.1053/jhep.2002.34613

[2] G. G. Vosnides, "Hepatitis C in Renal Transplantation," Kidney International, Vol. 52, No. 3, 1997, pp. 843-861. doi:10.1038/ki.1997.403

[3] B. J. Pereira and A. S. Levey, "Hepatitis C Virus Infection in Dialysis and Renal Transplantation," Kidney International, Vol. 51, No. 4, 1997, pp. 981-999. doi:10.1038/ki.1997.139

[4] R. D. Bloom, G. Sayer, K. Fa, et al., "Outcome of Hepatitis C Virus-Infected Kidney Transplant Candidates Who Remain on the Waiting List," American Journal of Transplantation, Vol. 5, No. 1, 2005, pp. 139-144. doi:10.1111/j.1600-6143.2004.00652.x

[5] A. Brüchfeld, H. Wilczek and C. G. Elinder, "Hepatitis C Virus Infection, Time in Renal Replacement Therapy, and Outcome after Kidney Transplantation,” Transplantation, Vol. 78, No. 5, 2004, pp. 745-750. doi:10.1097/01.TP.0000131948.29742.24

[6] C. O. Stehman-Breen, S. Emerson, D. Gretch, et al., "Rise of Death among Chronic Dialysis Patients Infected with Hepatitis C Virus," American Journal of Kidney Diseases, Vol. 32, No. 3, 1998, pp. 629-634. doi:10.1016/S0272-6386(98)70027-7

[7] S. Sezer, F. N. Ozdemir, A. Akcay, et al., "Renal Transplantation Offers a Better Survival in HCV Infected ESRD Patients,” Clinical Transplantation, Vol. 18, No. 5, 2004, pp. 619-623. doi:10.1111/j.1399-0012.2004.00252.x

[8] B. J. Pereira, "Hepatitis C Infection and Post-Transplan- tation Liver Disease," Nephrology Dialysis Transplantation, Vol. 10, No. 1, 1995, pp. 58-67.

[9] B. J. Pereira, T. L. Wright, C. H. Schmid, et al., "The Impact of Pre-Transplantation Hepatitis C Infection on the Outcome of Renal Transplantation,” Transplantation, Vol. 60, No. 8, 1995, pp. 799-805.

[10] M. A. Gentil, J. L. Rocha, G. Rodrigues-Algarra, et al., "Impaired Kidney Transplant Survival in Patients with Antibodies to Hepatitis C Virus," Nephrology Dialysis Transplantation, Vol. 14, No. 10, 1999, pp. 2453-2460. doi:10.1093/ndt/14.10.2455

[11] C. A. Stempel, J. Lake, G. Kuo, et al., "Hepatitis C Virus Infection and Renal Transplantation," Transplantation, Vol. 55, No. 2, 1993, pp. 273-276. doi:10.1097/00007890-199302000-00008

[12] E. P. Lasmar, M. F. Lasmar, L. F. Lasmar, et al., "LongTerm Impact of Hepatitis C in Renal Transplant Recipients-Preliminary Data,” Journal Brasileiro de Transplantes, Vol. 11, No. 2, 2008, pp. 915-917.

[13] G. M. Sahin, S. Sahin, G. Kantarcig and H. Ergin, "Impact of Hepatitis C Virus Infection on Patient and Graft Survival in Kidney Transplantation," Transplantation Proceedings, Vol. 38, No. 2, 2006, pp. 499-501. doi:10.1016/j.transproceed.2006.01.007

[14] S. Pedroso, L. Martines, I. Fonseca, et al., "Impact of Hepatits C Virus on Renal Transplantation: Association with Poor Survival,” Transplantation Proceedings, Vol. 38, No. 6, 2006, pp. 1890-1894. doi:10.1016/j.transproceed.2006.06.065

[15] Corrêa Jr, F. D. Rocha, L. F. Gonçalves and R. C. Manfro, "Long Term Effect of Hepatitis B and C Virus on the Survival of Kidney Transplant Patients," Revista da Associação Médica Brasileira, Vol. 49, No. 4, 2003, pp. 389-394.

[16] J. M. Morales and J. M. Campistol, "Transplantation in the Patient with Hepatitis C," Journal of the American Society of Nephrology, Vol. 11, No. 7, 2000, pp. 13431353.

[17] C. H. Legendre, V. Garrigue, C. Le Bihan, et al., "Harmful Long-Term Impact of Hepatitis C Virus Infection in Kidney Transplant Recipients,” Transplantation, Vol. 65, No. 5, 1998, pp. 667-670.

doi:10.1097/00007890-199803150-00011

[18] D. Roth, K. Zucker, R. Cirocco, et al., “The Impact of Hepatitis C Virus Infection on Renal Allograft Recipients," Kidney International, Vol. 45, No. 1, 1994, pp. 238-244. doi:10.1038/ki.1994.29

[19] Y. Kokado and S. Takahara, "Ichimaru Netal: Clinical Outcome of HCV Infection after Renal Transplantation,” Transplantation Proceedings, Vol. 32, No. 7, 2000, pp. 1940-1943. doi:10.1016/S0041-1345(00)01503-7

[20] G. A. Knoll, M. R. Tankersle, L. Y. Lec, et al., “The Impact of Renal Transplantation on Survival in Hepatitis C Positive End-Stage Renal Disease Patients," American Journal of Kidney Diseases, Vol. 29, No. 4, 1997, pp. 608-614. doi:10.1016/S0272-6386(97)90345-0

[21] J. M. Morales, B. Domingues-Gil, D. Sanz-Gajardo, et al., "The Influence of Hepatitis B and Hepatitis C Vírus In- 
fection in the Recipient on Late Allograft Failure," Nephrology Dialysis Transplantation, Vol. 19, No. 3, 2004, pp. 572-576.

[22] B. J. Pereira, et al., "Effects of Hepatitis C Infection and Renal Transplantation on Survival in End-Stage Renal Disease,” Kidney International, Vol. 53, No. 5, 1998, pp. 1374-1381. doi:10.1046/j.1523-1755.1998.00883.X

[23] W. C. Lee, K. H. Shu, C. H. Cheng, et al., "Long-Term Impact of Hepatitis B, C Virus Infection on Renal Transplantation," American Journal of Nephrology, Vol. 21, No. 4, 2001, pp. 300-306. doi:10.1159/000046265

[24] J. M. Morales, "Renal Transplantation in Patients Positive for Hepatitis B or C,” Transplantation Proceedings, Vol. 30, No. 5, 1998, pp. 2064-2069. doi:10.1016/S0041-1345(98)00542-9

[25] G. G. Yosnides, "Hepatitis C in Renal Transplantation,” Kidney International, Vol. 52, No. 3, 1997, pp. 843-861. doi:10.1038/ki.1997.403

[26] A. Yildiz, Y. Tutuncu, H. Yazici, et al., “Association be- tween Hepatitis C Virus Infection and Development of Post Transplantation Diabetes Mellitus in Renal Transplant Recipients,” Transplantation, Vol. 74, No. 8, 2002, pp. 1109-1113. doi:10.1097/00007890-200210270-00009

[27] A. Corell, J. M. Morales, A. Mandrono, et al., "Immunosuppression Induced by Hepatitis C Virus Infection Reduces Acute Renal Transplant Rejection,” The Lancet, Vol. 346, No. 8988, 1995, pp. 1497-1498. doi:10.1016/S0140-6736(95)92520-1

[28] G. Manga, S. Sahin, G. Kantarci, et al., "Impact of Hepatitis C Virus Infection on Patient and Graft Survival in Kidney Transplantation,” Transplantation Proceedings, Vol. 38, No. 2, 2006, pp. 499-501. doi:10.1016/j.transproceed.2006.01.007

[29] C. O. Stehman-Breenco, S. Emerson, D. Gretch, et al., "Rise of Death among Chronic Dialysis Patients Infected with Hepatitis C Virus," American Journal of Kidney Diseases, Vol. 32, No. 4, 1998, pp. 629-634. doi:10.1016/S0272-6386(98)70027-7 